of RA. Evidence of the incremental scale of these multimorbidity costs will usefully inform RA interventions and policies.

Objectives: The aim of this study was to describe how multimorbidity impacts on the cost-of-illness, including direct and indirect costs, in patients with RA.

Methods: The Scottish Early Rheumatoid Arthritis (SERA) is a registry of patients newly presenting with RA since 2011. It contains data on patient characteristics, clinical outcomes, health-related quality of life, and employment status data. These data were linked to routinely recorded hospital admissions and primary care prescribing data. Direct costs were estimated by applying relevant unit costs to healthcare resource use quantities. Indirect cost estimates were obtained from information on employment status and hospital admissions, valued by age and sex specific wages. Two-part models (probit followed by generalized linear model) were used to estimate direct and indirect costs, adjusting for age, gender, and functional disability. The Charlson Comorbidity Index (CCI) score was calculated using patient ICD-10 diagnoses from hospital records. The number of comorbidities was categorized into "RA alone", "single comorbidity" and "multimorbidity (>1 comorbidity)".

Results: Data were available for 1,150 patients, $65.7 \%$ were female and a mean age of $57.5 \pm 14$ years. The majority of patients only had RA (54.1\%), followed by a single comorbidity (23.4\%) and multimorbidity (22.5\%). Annual total costs were significantly higher for patients with multimorbidity $(£ 6,66995 \% \mathrm{Cl} £ 4,871$ $£ 8,466$; OR $11.395 \% \mathrm{Cl} 8.14-15.87)$ and for patients with a single comorbidity (£2,075 95\% Cl £1,559-£2,591; OR 3.52 95\% Cl 2.61-4.79), when compared with RA alone (£590). The excess costs were mainly driven by direct costs ( 6,281 versus $£ 1,875$ versus $£ 556)$. Although the difference in indirect costs between patients with multimorbidity and a single comorbidity were not statistically significant ( $£ 1,218$ versus $£ 914, p=0.11$ ), patients with multimorbidity were associated with significantly higher costs than those with RA only (£594, $p<0.01$ ). Conclusion: The presence of comorbidity contributes significant excess to both direct and indirect costs among RA patients. In particular, patients with multimorbidity incurred substantially higher direct costs than those with a single comorbidity or RA only.

Acknowledgements: The study analysed the data from the Scottish Early Rheumatoid Arthritis (SERA) study with a linkage to routinely recorded health data from Information Service Division, National Service Scotland. We would like to thank all the patients, clinical and nursing colleagues who have contributed their time and support to the study, the SERA steering committee for the approval, and Allen Tervit from the Robertson Centre for Biostatistics, University of Glasgow for the timely technical supports.

Disclosure of Interests: Ping-Hsuan Hsieh: None declared, Claudia Geue: None declared, Olivia Wu Consultant of: OW has received consultancy fees from Bayer, Lupin and Takeda outside the submitted work., Emma Mclntosh: None declared

DOI: 10.1136/annrheumdis-2021-eular.1817

\section{POS0531 $\quad$ FACTORS ASSOCIATED WITH BASELINE HYPERTENSION IN EARLY RHEUMATOID ARTHRITIS: DATA FROM A REAL-WORLD LARGE INCIDENT COHORT}

B. Hadwen ${ }^{1}$, S. Stranges ${ }^{1,2,3}$, N. Klar ${ }^{1}$, K. Bindee ${ }^{4}$, J. Pope ${ }^{5}$, S. J. Bartlett ${ }^{6,7}$, G. Boire ${ }^{8}$, L. Bessette ${ }^{9}$, C. Hitchon ${ }^{10}$, G. Hazlewood ${ }^{11}$, E. Keystone ${ }^{4}$, O. Schieir ${ }^{12}$, C. Thorne ${ }^{13}$, D. Tin $^{13}$, M. F. Valois ${ }^{6}$, V. Bykerk ${ }^{14,15}$, L. Barra ${ }^{1,3,5}$ on behalf of on behalf of CATCH Investigators. ${ }^{1}$ University of Western Ontario, Epidemiology and Biostatistics, London, Canada; ${ }^{2}$ University of Western Ontario, Family Medicine, London, Canada; ${ }^{3}$ Lawson Health Research Institute, London, Canada;

${ }^{4}$ University of Toronto, Sinai Health System, Toronto, Canada; ${ }^{5}$ University of Western Ontario, Department of Medicine, London, Canada; ${ }^{6}$ McGill University, Department of Medicine, Montreal, Canada; ${ }^{7}$ Johns Hopkins University, Department of Medicine, Baltimore, United States of America; ${ }^{8}$ Université de Sherbrooke, Department of Medicine, Sherbrooke, Canada; ${ }^{9}$ Université de Laval, Department of Medicine, Quebec City, Canada; ${ }^{10}$ University of Manitoba, Department of Medicine, Winnipeg, Canada; ${ }^{11}$ University of Calgary, Department of Medicine, Calgary, Canada; ${ }^{12}$ University of Toronto, Dalla Lana School of Public Health, Toronto, Canada; ${ }^{13}$ Southlake Regional Health Center, Division of Rheumatology, Newmarket, Canada; ${ }^{14}$ Weill Cornell Medical College, Hospital for Special Surgery, New York City, United States of America; ${ }^{15}$ University of Toronto, Department of Medicine, Toronto, Canada

Background: It is not well understood why hypertension (HTN) is so common in rheumatoid arthritis (RA) patients. Reported prevalence of HTN in RA patients ranges from $4-73 \%$.(1)

Objectives: This study explored the prevalence of HTN at time of RA diagnosis and which demographic, behavioural and clinical factors were associated with HTN

Methods: Data from the Canadian Early Arthritis Cohort (CATCH), a prospective inception cohort of patients with RA $<1$ year duration, were used to analyze baseline demographic, behavioural and clinical characteristics associated with HTN, which was reported by physicians. Univariate logistic regression models were created to explore associations with baseline HTN. A multivariate logistic regression model was built based on goodness of fit indicated by likelihood ratio tests. Variables included in the model were age, sex, race, body mass index (BMI), education smoking, alcohol servings, seropositivity, disease activity and comorbidities.

Results: In total, 2052 subjects were included with mean $( \pm S D)$ age of $55( \pm 14$ years and symptom duration $5.60(5.47,5.73)$ months, $71 \%$ of subjects were female and $85 \%$ were Caucasian. HTN was reported in $26 \%$ of subjects at baseline. Hypertensive subjects were older and more likely to be male. Other factors significantly associated with HTN at baseline were lower education, ever smoking, high BMI, diabetes, hyperlipidemia, worse RA disease activity, longer duration of RA symptoms being seropositive, as well as the use of NSAIDs and/or corticosteroids (Table 1). In multivariable analysis HTN was associated with older age, overweight and obese BMI, diabetes, and hyperlipidemia. Expression of anti-citrullinated protein antibodies was inversely associated with HTN (Table 1). Other RA disease factors and treatments were not significantly associated with HTN on multivariable analysis.

Table 1. Results of univariate and multivariate logistic regression analyses exploring the association between baseline characteristics and HTN in early RA.

\begin{tabular}{|c|c|c|c|}
\hline & & $\begin{array}{l}\text { Univariate Logistic } \\
\text { Regression }\end{array}$ & $\begin{array}{l}\text { Multivariable } \\
\text { Logistic } \\
\text { Regression }\end{array}$ \\
\hline & Variable & Crude OR $(95 \% \mathrm{Cl})$ & $\begin{array}{c}\text { Adjusted OR } \\
(95 \% \mathrm{Cl})\end{array}$ \\
\hline \multirow[t]{5}{*}{ Socio-Demographic } & 20-39 years old & $0.15(0.07,0.26)$ & $0.14(0.05,0.34)$ \\
\hline & $40-59$ years old & \multicolumn{2}{|c|}{ Reference } \\
\hline & $60-79$ years old & $2.81(2.26,3.50)$ & $2.26(1.65,3.11)$ \\
\hline & $80-99$ years old & $5.87(3.36,10.25)$ & $3.80(1.53,9.41)$ \\
\hline & Female & $0.55(0.45,0.68)$ & $1.10(0.78,1.54)$ \\
\hline \multirow[t]{5}{*}{ Lifestyle/Behavioural } & $\begin{array}{l}\text { Normal weight } \\
\left(18.5-24.9 \mathrm{~kg} / \mathrm{m}^{2}\right)\end{array}$ & \multicolumn{2}{|c|}{ Reference } \\
\hline & Overweight $\left(25-29.9 \mathrm{~kg} / \mathrm{m}^{2}\right)$ & $2.33(1.74,3.11)$ & $1.63(1.10,2.43)$ \\
\hline & Obese $\left(30+\mathrm{kg} / \mathrm{m}^{2}\right)$ & $3.19(2.38,4.27)$ & $2.84(1.91,4.23$ \\
\hline & Ever-smoking & $1.41(1.15,1.73)$ & $1.02(0.75,1.40)$ \\
\hline & Post-secondary education & $0.58(0.47,0.71)$ & $0.88(0.65,1.20)$ \\
\hline \multirow[t]{8}{*}{ Clinical Characteristics } & Symptom duration & $0.99(0.99,0.99)$ & $1.00(1.00,1.00)$ \\
\hline & DAS-28 & $1.09(1.09,1.17)$ & $1.02(0.92,1.13)$ \\
\hline & ACPA+ & $0.68(0.56,0.85)$ & $0.64(0.44,0.92)$ \\
\hline & $\begin{array}{l}\text { Corticosteroid use } \\
\text { pre-baseline }\end{array}$ & $1.37(1.04,1.81)$ & Omitted \\
\hline & NSAID use at baseline & $0.68(0.55,0.84)$ & Omitted \\
\hline & Diabetes & $5.62(4.09,7.73)$ & $3.20(1.99,5.15)$ \\
\hline & Hyperlipidemia & $4.75(3.74,6.03)$ & $2.80(1.94,4.02)$ \\
\hline & CVD & $15.59(3.35,72.64)$ & Omitted \\
\hline
\end{tabular}

DAS-28; Disease activity score 28, ACPA; Anti-citrullinated protein antibody, CVD Cardiovascular disease. Pre-baseline is 29 to 365 days before entering the cohort. Baseline is within 28 days before entering the cohort. Omitted variables either failed likelihood ratio test or were colinear. Additional variables tested but found insignificant: race, alcohol servings, depression, $R F+$, and use of DMARDs.

Conclusion: Approximately 1 in 4 diagnosed with RA had HTN reported by their rheumatologists, which is similar to that of the general population. This suggests that increased risk of HTN in RA patients may develop as RA disease or treatment time progresses. Factors that may be predictive of this excess risk will be explored in further analysis.

REFERENCES:

[1] Panoulas VF, Metsios GS, Pace AV, et al. Hypertension in rheumatoid arthritis. Rheumatology (Oxford) 2008;47:1286-98.

Acknowledgements: The CATCH study was designed and implemented by the investigators and financially supported through unrestricted research grants from: Amgen and Pfizer Canada - Founding sponsors since January 2007; AbbVie Corporation and Hoffmann-LaRoche since 2011; Medexus Inc. since 2013;, Merck Canada since 2017, Sandoz Canada, Biopharmaceuticals since 2019, Gilead Sciences Canada since 2020 and Fresenius Kabi Canada Ltd. since 2021. Previously funded by Janssen Biotech from 2011-2016, UCB Canada and Bristol-Myers Squibb Canada from 2011-2018, Sanofi Genzyme from 2016-2017, and Eli Lilly Canada from 2016-2020.

Disclosure of Interests: Brook Hadwen: None declared, Saverio Stranges: None declared, Neil Klar: None declared, Kuriya Bindee: None declared, Janet Pope Speakers bureau: UCB, Consultant of: AbbVie, Actelion, Amgen, Bayer, BMS Eicos Sciences, Eli Lilly \& Company, Emerald, Gilead, Janssen, Merck, Novartis Pfizer, Roche, Sandoz, Sanofi, UCB;, Grant/research support from: Abbvie, BMS, Eli Lilly \& Company, Merck, Roche, Seattle Genetics, UCB, Susan J. Bartlett Consultant of: Pfizer, UCB, Lilly, Novartis, Merck, Janssen, Abbvie, Gilles Boire Speakers bureau: Merck, BMS, Pfizer, Janssen, Grant/research support from: Amgen, Abbvie, BMS, Eli Lilly, Merck, Novartis, Pfizer, Sandoz, Louis Bessette Speakers bureau: Amgen, BMS, Janssen, Roche, UCB, AbbVie, Pfizer, Merck, Celgene, Sanofi, Lilly, Novartis, Consultant of: Amgen, BMS, Janssen, Roche, UCB, AbbVie, Pfizer, Merck, Celgene, Sanofi, Lilly, Novartis., Grant/research 
support from: Amgen, BMS, Janssen, Roche, UCB, AbbVie, Pfizer, Merck, Celgene, Sanofi, Lilly, Novartis., Carol Hitchon Grant/research support from: Pfizer and UCB Canada, Glen Hazlewood: None declared, Edward Keystone Speakers bureau: Amgen, AbbVie, Bristol-Myers Squibb, F. Hoffmann-La Roche Inc., Janssen Inc., Merck, Pfizer Pharmaceuticals, Sanofi Genzyme, UCB, Consultant of:: AbbVie, Amgen, AstraZeneca Pharma, Bristol-Myers Squibb Company, Celltrion, Myriad Autoimmune, F. Hoffmann-La Roche Inc, Genentech Inc, Gilead, Janssen Inc, Lilly Pharmaceuticals, Merck, Pfizer Pharmaceuticals, Sandoz, Sanofi-Genzyme, Samsung Bioepsis, Grant/research support from: AbbVie, Amgen, Gilead Sciences, Lilly Pharmaceuticals, Merck, Pfizer Pharmaceuticals, PuraPharm, Sanofi, Orit Schieir: None declared, Carter Thorne Speakers bureau: Medexus/ Medac, Consultant of: Abbvie, Centocor, Janssen, Lilly, Medexus/Medac, Pfizer, Grant/research support from: Amgen, Pfizer, Abbvie, Celgene, CaREBiodam, Novartis, Diane Tin: None declared, Marie-France Valois: None declared, Vivian Bykerk Consultant of: Amgen, BMS, Gilead, Sanofi-Genzyme/Regeneron, Scipher, Pfizer Pharmaceuticals, UCB, NIH, Lillian Barra: None declared DOI: 10.1136/annrheumdis-2021-eular.1835

\section{POS0532 AVERAGE PREDNISOLONE DOSE OF ONLY 1 MG PER DAY WAS RISK FACTOR FOR CLINICAL FRACTURES IN PATIENTS WITH RHEUMATOID ARTHRITIS - NINE- YEAR FINDINGS OF THE TOMORROW STUDY}

H. Yoshimura ${ }^{1}$, T. Koike ${ }^{2,3}$, K. Mamoto $^{4}$, Y. Sugioka ${ }^{2}$, T. Okano ${ }^{4}$, M. Tada $^{5}$, K. Inui ${ }^{6}$, H. Nakamura ${ }^{4} .{ }^{1}$ Izumi City General Hospital, Orthopaedic Surgery, Osaka, Japan; ${ }^{2}$ Center for Senile Degenerative Disorders (CSDD), Osaka City University Medical School, Orthopaedic surgery, Osaka, Japan; ${ }^{3}$ Search Institute for Bone and Arthritis Disease (SINBAD), Orthopaedic Surgery, Wakayama, Japan; ${ }^{4}$ Osaka City University Medical School, Orthopaedic Surgery, Osaka, Japan; ${ }^{5}$ Osaka City General Hospital, Orthopaedic Surgery, Osaka, Japan; ${ }^{6}$ Osaka Saiseikai Nakatsu Hospital, Orthopaedic Surgery, Osaka, Japan

Background: Previous cohort studies showed that the use of prednisolone (PSL) was a risk factor for clinical fractures in patients with rheumatoid arthritis (RA). However, there are few reports on relationship between PSL dose and clinical fractures. Objectives: The present study aimed to determine the effect of PSL dose on the incidence of clinical fractures in the RA patients treated with PSL.

Methods: We evaluated anthropoetric parameters, bone mineral density (BMD), disease activity score 28-erythrocyte sedimentation rate (DAS28-ESR), RA medication (methotrexate (MTX) dose, use of biologic disease modified anti-rheumatic-drugs (bDMARDs), and PSL dose) and the incidence of clinical fractures during nine years in RA patients who participant the TOMORROW study (UMIN000003876), which is a 10-years prospective cohort study. Data on clinical fracture was self-reported on the questionnaires. In this analysis, the data of RA patients treated with PSL at least once during nine-year period were evaluated. We analyzed the average dose of PSL until the incidence of the clinical fractures. The risk factor for clinical fractures were analyzed by using Cox proportional hazard model with adjustment for age, sex, body mass index (BMI), and smoking history. Results: We analyzed the data of 67 RA patients treated with PSL. Among them, median age was 61.8 year, 56 patients $(83.6 \%)$ were female, 47 patients $(70.1 \%)$ were never smoker and median disease duration was 12.1 year. The number of patients treated with PSL at baseline was 48 (69.1\%). During 9 years, 23 clinical fractures were observed in 67 patients, and the incidence of clinical fracture was $0.046 /$ person-year. In 19 patients, who were not treated with PSL at baseline but treated with PSL at least once during 9 years, 5 clinical fractures were observed. In 67 RA patients, Cox proportional hazard analysis revealed that baseline disease activities, BMD at thoracic vertebrae and medication were not significant risk factors for clinical fractures. However, average PSL dose of more than only $1 \mathrm{mg} /$ day was a significant risk factor for the incidence of clinical fracture (hazard ratio $(\mathrm{HR}): 2.80 ; \mathrm{p}=0.03$ ) (Table 1).

Table 1. Adjusted hazard ratio for clinical fractures in patients with rheumatoid arthritis treated with PSL.

\begin{tabular}{|c|c|c|c|}
\hline & $\begin{array}{l}{ }^{*} \text { Adjusted Hazard } \\
\text { ratio }\end{array}$ & $\begin{array}{l}95 \% \text { Confidence } \\
\text { interval }\end{array}$ & $\begin{array}{l}P \\
\text { value }\end{array}$ \\
\hline $\mathrm{CRP}(\mathrm{mg} / \mathrm{dL})$ & 1.29 & $0.88-1.91$ & 0.19 \\
\hline $\mathrm{RF}(\mathrm{IU} / \mathrm{mL})$ & 0.99 & $0.99-1.00$ & 0.07 \\
\hline ACPA (U/mL) & 0.99 & $0.98-1.00$ & 0.18 \\
\hline DAS28-ESR & 0.99 & $0.71-1.39$ & 0.97 \\
\hline BMD at thoracic vertebrae $\left(\mathrm{mg} / \mathrm{cm}^{2}\right)$ & 0.02 & $0.00-1.00$ & 0.05 \\
\hline bDMARDs use & 0.55 & $0.23-1.32$ & 0.18 \\
\hline Bisphosphonate use & 2.33 & $0.95-5.71$ & 0.07 \\
\hline average dose of MTX (mg/week) & 1.02 & $0.92-1.12$ & 0.74 \\
\hline average score of DAS28-ESR & 1.15 & $0.76-1.75$ & 0.52 \\
\hline average dose of PSL more than $1 \mathrm{mg} /$ day & 2.8 & $1.09-7.24$ & 0.03 \\
\hline
\end{tabular}

*Hazard ratio was adjusted for age, sex, body mass index (BMI), and smoking history. RF, Rheumatoid factor; ACPA, Anti-cyclic citrullinated peptide antibody; DAS28-ESR, disease activity score 28-erythrocyte sedimentation rate; BMD, Bone mineral density; bDMARDs, biologic disease modified anti-rheumatic-drugs; MTX, methotrexate; PSL, prednisolone.
Conclusion: In RA patients treated with PSL, average PSL dose of only $1 \mathrm{mg}$ day significantly increased the risk for the incidence of clinical fractures. Even for established RA patients, continuous use or initiation of low PSL dose was apparently significant risk factor for clinical fractures.

Disclosure of Interests: Hitoshi Yoshimura: None declared, Tatsuya Koike Grant/ research support from: Takeda Pharmaceutical, Mitsubishi Tanabe Pharma Corporation, Chugai Pharmaceutical, Eisai, Abbott Japan, Teijin Pharma, Banyu Pharmaceutical and Ono Pharmaceutical, Kenji Mamoto: None declared, Yuko Sugioka: None declared, Tadashi Okano: None declared, Masahiro Tada: None declared, Kentaro Inui Grant/research support from: Janssen Pharmaceutical K.K. and Astellas Pharma Inc, Hiroaki Nakamura: None declared DOI: 10.1136/annrheumdis-2021-eular.1868

\section{\begin{tabular}{|l|l}
\hline POS0533 & EFFECT OF CAROTID ULTRASOUND ON THE
\end{tabular} ACHIEVEMENT OF LDL-CHOLESTEROL TARGETS IN THE ROUTINE CLINICAL CARE OF PATIENTS WITH RHEUMATOID ARTHRITIS}

I. Ferraz-Amaro $^{1}$, A. Corrales ${ }^{2}$, N. Vegas-Revenga ${ }^{2}$, B. Atienza-Mateo ${ }^{2}$, V. Portilla ${ }^{2}$, R. Blanco ${ }^{2}$, J. Llorca ${ }^{2}$, M. A. González-Gay ${ }^{2} .{ }^{1}$ Hospital Universitario de Canarias, Division of Rheumatology, Santa Cruz de Tenerife, Spain; ${ }^{2}$ Hospital Universitario Marqués de Valdecilla, Division of Rheumatology, Santander, Spain

Background: Cardiovascular disease (CVD) risk in patients with rheumatoid arthritis (RA) is substantially elevated compared to the general population. In RA as in the general population, CVD control includes the detection and treatment of $\mathrm{CV}$ risk factors based, among others, on blood pressure, smoking, diabetes, and lipid profiles. Little is known about the real impact of the use of carotid ultrasound in the prevention of CVD in patients with RA.

Objectives: To determine whether the use of carotid ultrasound in the routine clinical care of patients with RA can improve the achievement of LDL-cholesterol targets over time.

Methods: We conducted a retrospective, real-world study of 327 RA patients in which a carotid ultrasound was performed as part of routine clinical care. Participants were followed from 2012 to 2018. LDL-c levels were measured before and after the carotid ultrasound intervention. The achievement of the LDL-c goals recommended by the international guidelines was compared before and after the carotid ultrasound. Predictive factors of achievement of LDL-cholesterol targets were studied.

Results: When considering the 2010 EULAR RA SCORE risk categories, serum LDL-c levels in the moderate CV risk category was significantly lower when follow-up finished $(126 \pm 33$ to $109 \pm 29 \mathrm{mg} / \mathrm{dl}, \mathrm{p}=0.000)$ (Table 1). This was not the case for other CV risk categories. Similarly, LDL-C goal attainment in the moderate CV risk category was significant higher at the end of the study compared to baseline. Based on the 2016 European Society of Cardiology LDL-c targets, the achievement of a LDL-cholesterol inferior to $115 \mathrm{mg} / \mathrm{dl}$ for the moderate $\mathrm{CV}$ risk category significantly increased from 35 to $64 \%(p=0.000)$ after follow-up. However, significant changes were not observed in this regard for the low, high, and very-high $\mathrm{CV}$ risk categories.

Table 1. LDL cholesterol serum levels and LDL goals differences between baseline and final follow-up

\begin{tabular}{|c|c|c|c|c|c|c|c|c|c|}
\hline & \multicolumn{5}{|c|}{$\mathrm{LDL}, \mathrm{mg} / \mathrm{dl}$} & \multicolumn{4}{|c|}{ LDL (mg/dl) ESC 2016 goals } \\
\hline & $\mathrm{n}$ & $\%$ & Baseline & $\begin{array}{c}\text { Final } \\
\text { follow-up }\end{array}$ & & Goal & Baseline & $\begin{array}{c}\text { Final } \\
\text { follow-up }\end{array}$ & $\mathrm{p}$ \\
\hline \multicolumn{10}{|c|}{2010 EULAR RA SCORE } \\
\hline Low & 120 & 37 & $116 \pm 37$ & $119 \pm 32$ & 0.081 & $<130$ & $68 \%$ & $66 \%$ & 0.99 \\
\hline Moderate & 195 & 60 & $126 \pm 33$ & $109 \pm 29$ & 0.000 & $<115$ & $35 \%$ & $64 \%$ & 0.000 \\
\hline High & 7 & 2 & $121 \pm 26$ & $104 \pm 22$ & 0.14 & $<100$ & $14 \%$ & $33 \%$ & 0.99 \\
\hline Very High & 5 & 0 & $131 \pm 41$ & $115 \pm 46$ & 0.080 & $<70$ & $0 \%$ & $20 \%$ & 0.99 \\
\hline
\end{tabular}

ESC: European Society of Cardiology; EULAR: European League Against Rheumatism. SCORE: Systematic COronary Risk Evaluation; RA: Rheumatoid Arthritis; LDL: Iow-density lipoprotein. Significant ' $p$ ' value are depicted in bold.

When patients with RA, regardless the SCORE risk they had, were divided between those that attained LDL-cholesterol target or not, those that achieved their LDL goal, were more frequently female and had less diabetes mellitus. Moreover, the probability of achieving LDL-cholesterol goal was higher in those with an inferior total cholesterol, LDL-c and atherogenic index at baseline. Interestingly, no differences were observed in both populations regarding the baseline use of statins, aspirin or hypertension treatment at baseline. Concerning disease related data when study started, no differences about disease duration and activity or treatments were observed between dose that reached LDL-cholesterol goal and those that did not.

Those that achieved LDL-c objectives had a higher decrease in smoking quit and a superior control of hypertension. Besides, in those that attained objectives a 